The Geneva Papers on Risk and Insurance, 21 (No. 79, April 1996), 284-292

\title{
Providing for Long-term Care: Insurance Vs. Trust Saving*
}

\author{
by Peter Zweifel **
}

\section{Introduction}

In the process of demographic ageing, there is a new risk facing the population of industrialized countries, the risk of needing long-term care (LTC). For example, the number of individuals aged eighty and older (who are believed to be most exposed to this risk) is predicted to grow from $6.3 \mathrm{mn}$. (1992) to $17.7 \mathrm{mn}$. by the year 2040 in the U.S. and from $1.65 \mathrm{mn}$. (1991) to $2.3 \mathrm{mn}$. by the year 2030 in Germany, [see Eisen (1992) and Bundesministerium der Finanzen (1990)].

One response to the problem is to introduce compulsory LTC insurance, as recently decided by the German parliament. This solution has the severe drawback of imposing something for which there is little private demand. As argued by Pauly (1990), a parent's demand for LTC insurance is undermined by a moral hazard effect because the child may decide to reduce his caregiving in favor of care provided by third parties, the cost of which is lowered by insurance. The imposition of compulsory LTC insurance tends to aggravate rather than relieve this problem.

Moreover, alternatives for financing LTC exist that are less susceptible to moral hazard effects. In particular, banks may provide for a trust saving contract tailored to the needs of individuals facing the risk of LTC, using their real property as collateral. Under a variant also known as reverse mortgage [Jacobs and Weissert (1986)], the homeowner is required to pay back the major part of his mortgage such that the net value of his/her real property attains a minimum value. In the event that the LTC risk materializes, the bank obtains title of ownership of the real property. In return, the elderly person receives a contribution towards covering the cost of LTC, retaining the right to live in his home as

\footnotetext{
* This is the revised version of a contribution presented to the Workshop on the Boundary between private and social insurance, Nottingham, 18 October 1994.

** Professor, Institute for Empirical Research in Economics, University of Zurich, Switzerland.
} 
long as he chooses. Through such a contract, the bank in fact assumes the risk of longevity very much like an insurer does [see e.g. Mayer and Simons (1994) for the different variants of reversed mortgage contracts].

Against this backdrop, the objective of this contribution is to examine and evaluate the relative merits of LTC insurance and trust saving as two instruments for meeting the risk of LTC, using a model of parent-child interaction.

The literature on parent-child interaction is characterized by a curious asymmetry. Typically, altruistic parents try to influence egoistic children, as e.g. in the model by Becker (1974). His «rotten kid theorem» posits that altruistic parents do not need to impose their will on their egoistic children because they can use transfer payments to induce the behavior they desire. However, in that model the child will never increase his wealth to the point of reducing total wealth jointly available to the two generations. It is this assumption that in fact limits the egoism on the part of the child and permits the parent to prevail. Bernheim et al. (1985) in their turn assume that the child values LTC activities positively at first but negatively beyond a value that the parent knows ex ante. Moreover they do not consider the possibility of LTC being provided by a third party, thus failing to recognize the incentive effects emanating from the different instruments used for financing LTC.

In this article, both parent and child are viewed as self-interested actors in a principalagent setting. However, the parent as the principal is assumed to be unable to sanction shirking on the part of the child when the LTC risk materializes. We will examine the question of whether moral hazard effects are indeed strong enough as to annihilate demand for private LTC insurance, as predicted by Pauly (1990) ${ }^{1}$. Moreover, we assess the moral hazard effects in an alternative instrument such as trust saving for LTC ${ }^{2}$.

The plan of this paper is as follows. The next section is devoted to expounding the elements of a two-generation model in which a parent has the option of buying LTC insurance or a trust saving contract in his/her attempt to deal with the financial risks of LTC. Both parent and child pursue their own interests, differing only with respect to their position in the life cycle. In the third and fourth sections, the child's optimization problem is analyzed in order to determine the effects of the purchase of LTC insurance and trust saving by the parent on his behavior. The fifth section builds on these results to predict the parent's optimal decision with regard to LTC insurance and trust saving, anticipating the child's opportunistic response to the incentives created. The final section is devoted to a comparative evaluation of the two instruments for dealing with the financial risk of LTC.

\section{The model}

In most formulations of the interaction between parent and child, child behavior is modeled differently from parental behavior. In particular, the parent is typically assumed to act in an altruistic manner when the interests of the child are involved. However, when

\footnotetext{
${ }^{1}$ Demand for private LTC insurance is also undermined by the existence of public welfare, as pointed out by Buchholz and Wiegard (1992). This problem is not considered here for simplicity.

${ }^{2}$ Distributional issues are entirely abstracted from. The reader interested in them is referred to Breyer (1991).
} 
it comes to decide about LTC, the parent deals with a mature offspring rather than a helpless baby, while the child may himself be a parent as well. These considerations call for a symmetric treatment of the two generations. One way to achieve this is to extend the model to cover three periods, in the guise of Hansson and Stuart (1989). During a previous period $(t=-1)$, the current parent was affected by the grandparent's risk of LTC (see upper part of Figure 1). At that time, he had to take certain decisions with regard to LTC to be given to the grandparent, which however are considered irreversible at time $t=0$, the period of interest. For one, the grandparent may have died already; moreover, dispositions made previously (such as referral to a home) can often be modified at exceedingly high cost only. To be sure, the parent's endowed wealth depends importantly on whether or not the grandparent's LTC risk materialized. However, the amount of wealth will be considered predetermined at time $t=0$ when the parent is about to make his decisions.

At $t=0$ the parent has three decisions to make. Having terminated his working life, work hours are assumed to be zero. This leaves consumption, the amount of LTC insurance purchased (reflected by the premium to be paid), and the amount of trust saving for financing LTC to be decided upon.

LTC insurance provides for partial coverage of the net cost of LTC, which is the difference between the time units of institutional care and the time contributed by the child, valued at a price. For example, if the care given by the child defers entry into a home by one year, this difference would be valued at a unit price of US $\$ 30,000$ (say). The part of the visible cost falling on the parent is determined by the rate of coinsurance, which in its turn depends negatively on the premium.

Figure 1: Interactions between generations in long-term care

Parent
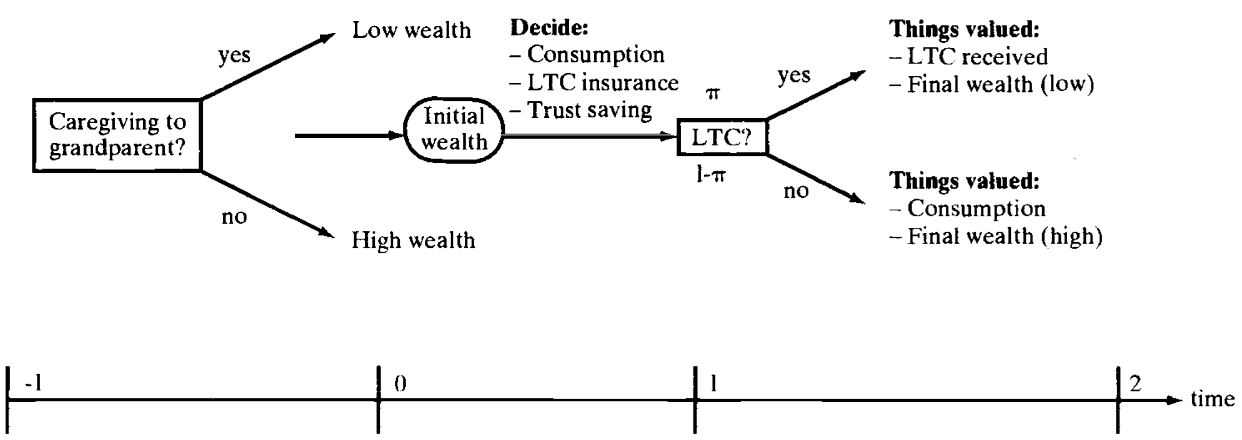

Child

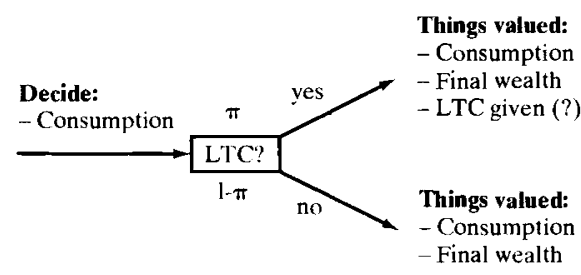


Trust saving for LTC amounts to specifying an amount that has to be paid in at $t=0$ and will be returned at $t=1$. In the event of LTC however, the bank takes over title of ownership of the real asset financed by the parent's payments [the house with mortgage reduced by this amount in the case of the 'reversed mortgage' proposed by Jacobs and Weissert (1986)]. Being a specialized market maker, the bank faces lower transaction costs when selling the asset than would its owner. Competitive pressure will ensure that this advantage must be shared with the contract partner, causing the bank to offer a rate of return in excess of the risk-free rate of interest in the event that the LTC risk materializes. This excess constitutes the leverage provided by trust saving.

At $t=1$, the parent may be in need of LTC or continue healthy to the end of his life. In the first event, his utility depends on the amount of care received from his child and his final wealth ${ }^{3}$. Consumption is considered unimportant in this situation, its cost being simply subsumed in the gross cost of LTC provided by third parties.

With probability $(1-\pi)$, the parent does not need LTC, causing his utility of the period to depend on consumption along with final wealth. Final wealth again is the balance of initial wealth, consumption in the two periods, and premium payments, with trust savings netting out (on a present value basis).

The lower part of Figure 1 shows the optimization problem of the child. In fact, at $t=0$ the child is in the same situation as his parent at time $t=-1$, who had to determine the amount of LTC and to plan final wealth. By giving care, the child sacrifices time available for work; on the other hand, he may count on receiving a higher bequest at the end of the period. In principle, the child's planning horizon should extend beyond $t=2$; however, for simplicity, it is assumed that (as in the case of the parent at the time) only the decision conceming caregiving has to be made, whereas the decisions with regard to consumption in a later phase of active life, the purchase of LTC insurance, and the accumulation of trust banking assets are deferred to a later period.

In the event of the parent needing LTC, the child values consumption, LTC provided, and final wealth. While consumption and wealth are considered to be positively valued, this is an open question for LTC provided. Some children may like caregiving, while others may dislike it. Mathematical analysis shows that the implications of the model do not depend on this issue, which adds to the generality of the analysis [see Zweifel and Strüwe (1996)]. Optimization proceeds under the wealth constraint stating that savings out of labor income plus inherited wealth make up the disposable wealth of the child. On the one hand, a greater amount of LTC activity requires working time to be reduced, causing labor income and hence disposable wealth to be smaller, ceteris paribus (see Figure 1 again). On the other hand, the child can count on a larger bequest if he/she contributes to LTC, which serves to add to disposable wealth.

Finally, in the event that the parent's LTC risk does not materialize, no LTC has to be provided, causing the labor income of the child to be larger. Moreover, the child receives the bequest.

\footnotetext{
${ }^{3}$ The inclusion of final wealth in the parent's utility function is not meant to reflect an (altruistic) bequest motive but the uncertainty about time of death (which however is not modeled formally here).
} 
Conclusion 1: LTC activity may be modeled using a principal-agent representation of the relationship between child and parent without assuming anything but selfinterest on both sides. In particular, caregiving on the part of the child need not be defined as a good or a bad.

\section{Optimization by the child}

In keeping with the sequence of decisions shown in Figure 1, the child first fixes consumption, i. e. a certain standard of living for the rest of his working life. It is only later, at the time when the LTC risk materializes, that the decision with regard to LTC will be made. Given that the consumption decision is made under risk, the optimization problem at $t=0$ is one of maximizing expected utility,

At time $t=1$, consumption is predetermined, leaving only the extent of LTC provided as a decision variable [see Zweifel and Strüwe (1996) for details]. The necessary condition for an optimum takes into account that LTC provided also has an indirect impact on the child's utility through its effect on final wealth [see Figure 1 again]. It can be shown that the wage rate of the potential caregiver is decisive. In the following, it is assumed that the wage rate attained or attainable on the labor market, indicating the marginal opportunity cost of providing LTC differs from its marginal return in the guise of cost sharing avoided. Since LTC insurance is contracted by the parent and not the child, such an inequality will be the rule rather than the exception. Moreover, even in the well-developed market for private health insurance, policies tend to be rather standardized with regard to the rate of coinsurance. The amount of product differentiation is likely to be even less in a market for LTC insurance which is about to develop, implying that the opportunity cost equals avoided financial cost only in exceptional cases.

The solutions may be characterized as follows. If the wage rate is relatively low, the child has an interest in providing LTC. Should caregiving be positively valued regardless of its extent, complete specialization in LTC is predicted. If on the other hand caregiving is a bad or becomes one with an increasing amount of caregiving, the extreme solution, "no LTC» follows. If the wage rate is relatively high (exceeding the net cost of care in a home), an intermediate solution is again predicted. Evidently, the question of whether giving LTC is a good or a bad does not matter here.

\section{Child behavior}

\subsection{Response to parent's purchase of LTC insurance}

This subsection is devoted to the analysis of the child's response to the purchase of (additional) LTC insurance by his parent. The predicted response is of great importance to the parent, who values care given by his/her child in the event that he/she should have to rely on LTC (see section 5 below).

The purchase of LTC insurance serves to disturb the optimality conditions of the child, who will adjust his decision variables (consumption, caregiving) in a way as to neutralize the impacts of this disturbance. For details, the reader is again referred to Zweifel and Strüwe (1996). There, it is shown that the child's response to the parent's purchase of LTC insurance is to reduce his caregiving if his/her wage rate is smaller than the net cost of 
institutional care per unit time. The response is ambiguous in the care where the wage rate attained (or attainable) in the labor market exceeds the net cost per unit time.

Conclusion 2: The child's predicted response to LTC insurance purchased by the parent depends importantly the wage rate that the child earns or could earn on the labor market. If this wage rate is below the net price of LTC provided by a third party (after deduction of insurance benefits), improved coverage against the risk of LTC causes the amount of his/her own caregiving to decrease. If however his/her wage exceeds the net price of LTC, additional coverage has an ambigous impact.

Intuitively, this conclusion hinges on the fact that the child can afford to reduce his own caring activity thanks to increased LTC insurance coverage, being less constrained to spare his wealth by giving care himself. This holds true quite independently of whether the child likes or dislikes giving care. In the process of adjustment, the marginal utility of wealth decreases; this effect may possibly cause the child to provide more care, but only if this has greater influence on his final wealth than does the change of LTC insurance coverage, i.e. only if the attainable wage rate exceeds the net money price of care provided by a third party.

\subsection{Response to parent's trust saving for LTC}

The child's optimal reaction to trust saving for LTC by the parent also depends on the child's wage rate, with a curtailment of caregiving if his/her wage falls short of the net cost per unit time of institutional care.

However, this response is in all likelihood smaller than in the case of LTC insurance because insurance has far more leverage in the LTC state than does trust saving, where the excess return provided by the bank as the market maker for the asset amounts to maybe one or two percentage points.

Conclusion 3: The child's predicted response to trust saving for LTC by the parent depends on his/her wage rate in the same way as in the case of LTC insurance (see Conclusion 2). However, it is less likely to be negative than in the case of LTC insurance in the sense that a lower value of the wage rate suffices to make it indeterminate.

\section{Optimization by the parent}

\subsection{The child as an agent}

The particularity of the parent's situation can be seen in that he cannot control the decisions of his child, symbolized by the child's choices, at the time the LTC risk is about to materialize (see Figure 1 again). For one, observability with regard to consumption may frequently be lacking; moreover and more importantly, the cost of sanctioning the child for deviating with his/her caring activity from the value deemed optimal by the parent may well be excessive for a parent in need of LTC. For these reasons, the parent is assumed to treat his/her child like an agent whose optimal decisions must be accepted as given. In order to ensure so-called incentive compatibility, the child's necessary conditions for an 
optimum enter the parent's optimization problem in the guise of constraints.

Since the child may always renege on the implicit contract with the parent by breaking the family ties, the parent must also observe a so-called participation constraint.

\subsection{Optimal purchase of LTC insurance from the parent's point of view}

When deciding about LTC insurance, the parent evidently must take the child's likely responses into account, which in their turn modify his own expected utility as well as the incentive compatibility and participation constraints.

Given a marginally fair premium, a change in insurance coverage would have no wealth effect; nevertheless, a risk-averse parent would buy insurance. However, the fact that the child may reduce his/her caregiving may easily cause the parent not to buy LTC coverage.

In the case of a marginally unfair premium, still more parents refrain from purchasing LTC insurance regardless of the incentive compatibility and participation constraints imposed on them.

However, there are additional influences, emanating from the agency relationship with the child. Their total effect is ambiguous. On the one hand, buying LTC insurance serves to reduce the parent's dependence on incentive compatibility on the part of his child. On the other hand, if LTC is bad for the child, while the welfare of the parent strongly depends on keeping in touch with the child, then doing without insurance may again become optimal.

If the child can count on earning a high wage rate, his response to LTC insurance is indeterminate, permitting any personal interest of the parent in LTC insurance to become decisive. In addition, it can be shown [Zweifel and Strüwe (1996)] that the participation constraint need not militate against its purchase in this case, permitting the purchase of coverage.

Conclusion 4: If the child curtails his caring activity in response to the parent's purchase of LTC insurance (a response that has to be expected in case of a low wage rate) the purchase of LTC insurance would run counter to the parent's personal interest in many cases. If however the child can count on earning a high wage rate, LTC insurance may be in the parent's interest.

\subsection{Optimal trust saving from the parent's point of view}

It is clear that many a parent will often refrain from trust saving for LTC as well. At the same time, the set of parameter values resulting in such a decision is smaller here than in the case of LTC insurance, mainly because its moral hazard effect on the child is smaller.

Conclusion 5: Providing for LTC through trust saving tends to be more in the parent's personal interest than the purchase of LTC insurance. However, the participation constraint imposed by the child may nevertheless annihilate private demand for trust saving for LTC. 


\section{Comparative evaluation and conclusions}

These concluding remarks are based on a model that does not posit altruism between generations. When deciding about providing for his/her long-term care (LTC) risk, the parent nevertheless cannot regard his/her own interests in the narrow sense but has to take the likely responses on the part of the child into account. In particular, buying LTC insurance often is not in the parent's personal interest because it is exactly in the case of the child having a comparatively low wage rate, a situation basically encourageing caregiving, that he has to count on a reduction of LTC activity on the part of the child. The moral hazard effect discussed by Pauly (1990) thus strikes precisely where its impact is greatest. As long as most care is given by daughters that are not in the labor market, this likely response undermines a parent's possible interest in LTC insurance in many cases. Pressure to purchase LTC insurance seems to originate mainly from the necessity of keeping generational relationships compatible with the child's pursuing his/her own objectives as a self-interested agent ${ }^{5}$.

The moral hazard effects of trust saving are less pronounced and may even be neutralized by its positive wealth effect. Still, the need to make the child participate in the provision of LTC can be of overriding importance, causing parent's interest in an instrument of the 'reverse mortgage' type to vanish as well [as documented empirically by e.g. Venti and Wise (1991) or Mayer and Simons (1994)]. Generally, the agency role of the child serves to reinforce the parent's interest in trust saving only under rather restrictive conditions. In particular, the parent's welfare must not depend strongly on the participation decisions of his child.

In sum, trust saving for LTC seems to be less affected by problems of the moral hazard type than is LTC insurance because it gives less incentives to those who have traditionally provided much of informal caregiving to diminish their efforts. The additional question that should be addressed in the future is whether possibly a combined use of both instruments might serve to avoid their drawbacks while profiting from their synergies.

${ }^{5}$ For a more detailed discussion of the pros and cons of compulsory LTC insurance, see Zweifel and Striiwe (1994). 


\section{REFERENCES}

BECKER, G. S., 1965, A Theory of the Allocation of Time, Economic Journal, p. 493-517.

BECKER, G. S., 1974, Theory of Social Interactions, Joumal of Political Economy, 82, p. 1063-1093.

BERNHEIM, B., A. SHLEIFER and L. SUMMERS, 1985, The Strategic Bequest Motive, Journal of Political Economy, 93, p. 1045-1076.

BREYER, F., 1991, Verteilungswirkungen unterschiedlicher Formen der Pflegevorsorge (Distributional Impacts of Alternative Forms of Provision for Long-term Care), Finanzarchiv NF $49(1), 84-103$.

BUCHHOLZ, W. and W. WIEGARD, 1992, Allokative Ueberlegungen zur Reform der Pflegevorsorge (Allocative Considerations Concerning the Reform of Provision for Long-term Care), Jahrbücher für Nationalökonomie und Statistik, 209, p. 441-457.

Bundesministerium der Finanzen (ed.), 1990, Stellungnahme dcs Wissenschaftlichen Beirates beim Bundesministerium der Finanzen zur Finanzierung von Pflegekosten (Report of the Scientific Advisery Body to the Federal Ministry of Finance Concerning the Financing of Long-term Care Costs), Bonn.

EISEN, R., 1992, Alternative Sicherungsmoglichkeiten bei Pflegebedürftigkeit, (Alternatives for Dealing with Long-term Care Risk), Sozialer Fortschritt, 41, p. 236-241.

FRIEDMAN, B. M. and M. J. WARSHAWSKY, 1990, The Cost of Annuities: Implications for Saving Behavior and Bequests, Quarterly Journal of Economics, p. 135-154.

HANSSON, I. and Ch. STUART, 1989, Social Security as Trade Among Living Generations, American Economic Review, 79, p. 1182-1195.

JACOBS, B. and W. G. WEISSERT, 1986, Catastrophic Costs of Long-Term Care, Joumal of Policy Analysis and Management, 5, p. 378-383.

MAYER, C.J. and K.V. SIMONS, 1994, Reverse Mortgages and the Liquidity of Housing Wealth, Journal of the American Real Estate and Urban Economics Association, 22 (2), 235-255.

PAULY, M. V., 1990, The Rational Nonpurchase of Long-term Care Insurance, Journal of Political Economy, 95, p. 153-168.

RICHTER, W. F., 1993, Bequeathing Like a Principal, Paper contributed to the annual meeting 1993 of the Verein für Sozialpolitik.

VENTI, S.F. and B.A. WISE, 1991, Ageing and the Income Value of Housing Wealth, Journal of Public Economics, 44, p. 371-397.

ZWEIFEL, P. and W. STRÜWE, 1996, Long-term care insurance and trust saving in a two generation model, in: Eisen, R. and Sloan, F.A. (eds.), Altematives for Ensuring Long-term Care, Kluwer: Dordrecht (forthcoming). 